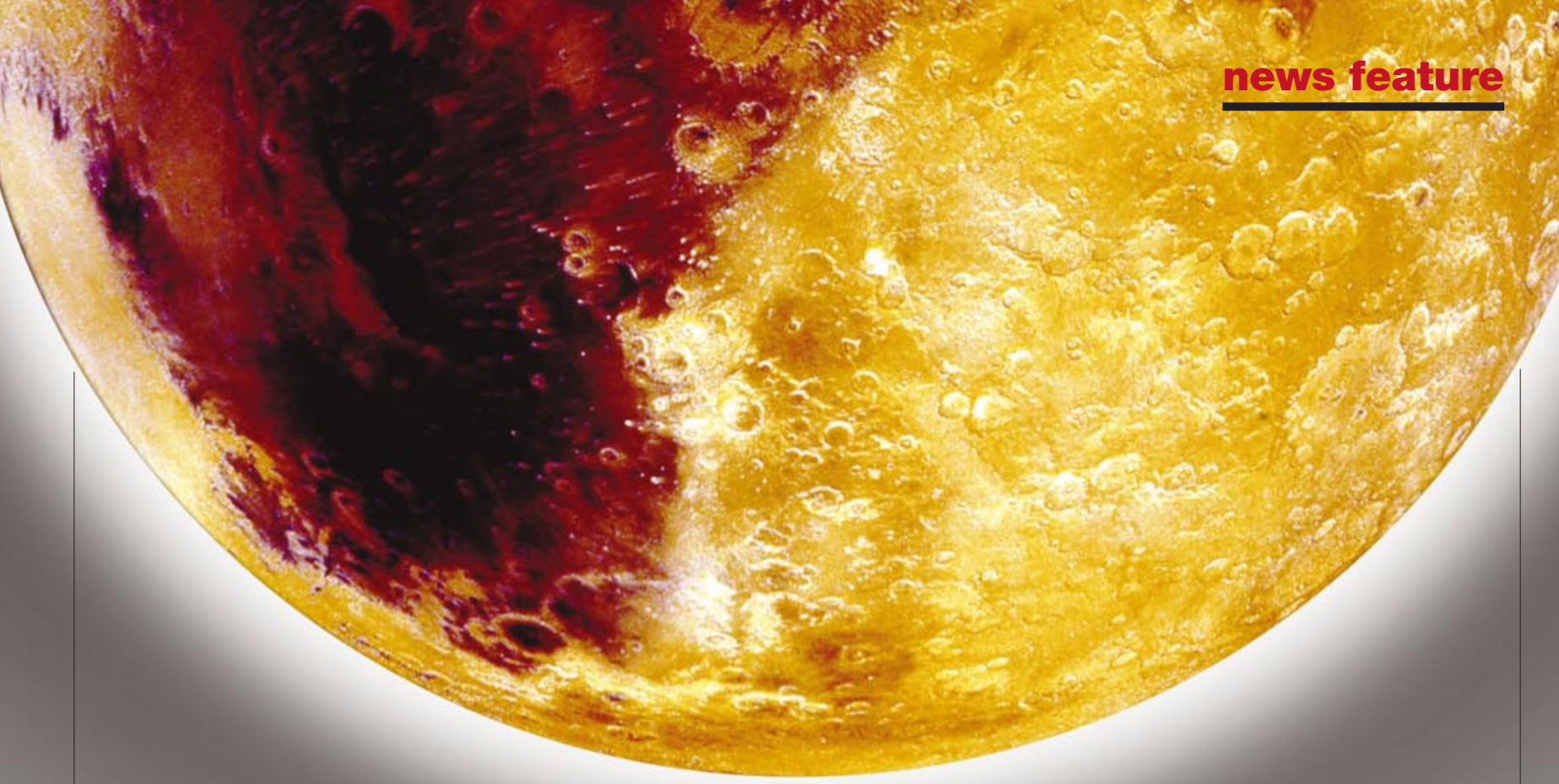

\title{
Mars attracts!
}

\author{
Interest in the red planet is about to peak, as three missions prepare \\ to join the hunt for water and life on one of our closest neighbours.
}

A strology is rightly maligned, but the position of the planets has at least some predictive power. Every 26 months, Mars and Earth come into an alignment that minimizes the fuel needed to journey between the two. And every time that happens, Mars researchers find themselves excited, nervous and overworked, as they prepare to launch spacecraft in which they have invested years of effort.

That alignment is upon us again, and three new craft are scheduled to take off next month. In the pages that follow, Nature introduces those missions in graphical form (see page 474), and reveals the human stories behind the hardware.

If some involved feel worried, it is partly because they have previously worked on craft that launched but never made it to Mars (see page 477). But such failures have not deterred the world's space agencies. The Japanese probe Nozomi is already en route to Mars, and many other missions are on the drawing board to take advantage of future favourable planetary alignments.

Some planetary scientists feel that the degree of attention lavished on Mars is unwarranted. Mars is already the best-mapped planet after the Earth, and we know more about its climate and geology than that of any of our other neighbours. Yet the public, funding agencies and scientists are still drawn to the red planet, for the simple reason that extraterrestriallife may once have existed there.

In the case of NASA's two new Mars Exploration Rovers, the search for life will be conducted through a proxy search for water. Liquid water is not thought to exist on Mars today. But water would have been necessary if life were present in the past, so the rovers will hunt for its geological calling card.

At the dawn of each martian day, the rovers will receive instructions based on images sent back to the Earth by their four sets of onboard cameras. They will be told what site to visit and what to do there, but not how to get there - signals take around ten minutes to travel between Mars and Earth, so onboard navigation software will be used to avoid obstacles in the rovers' paths. Once a target site has been reached, numerous instruments can be deployed: grinders will drill into the rock, for example, and magnets will be used to collect particles for further analysis onboard the rover.

The Beagle 2 lander, part of the Mars Express mission run by the European Space Agency (ESA), will be stationary, but will make up for its sedentary nature by deploying some innovative equipment (see page 476). One example is the 'mole', a bicycle-pump-shaped device that will crawl along the planet's surface and can be directed vertically into the soil by retracting and unleashing a pair of spring- loaded weights. The device will collect samples in a cavity at its head; winding in the mole's power cable allows the samples to be retrieved. A mass spectrometer on Beagle 2 will then reveal, amongst other things, the relative amounts of different carbon isotopes in the rock. Living organisms, such as bacteria, take up these isotopes in different ways, so the analysis could reveal whether life was present when the rocks formed.

Both the NASA and ESA landers will have relatively short missions - around three and six months, respectively. But in the sky above, two orbiting craft will continue to study Mars, probably until 2006. Mars Express will probe the composition of the martian atmosphere and surface. Nozomi, which will arrive four years later than planned because a malfunctioning thruster forced engineers to adjust its route, will study how the planet is buffeted by the solar wind, the stream of charged particles emitted by the Sun.

Such mishaps as befell Nozomi are common in planetary exploration - and so the nerves of ESA and NASA scientists are likely to be frayed over the next couple of months. Once the launches are is over, the respite will only be temporary. Expect high levels of anxiety and edginess among Mars researchers early next year, as the crafts on which they have staked so much approach their final destination. Jim Giles, associate news and features editor. 